\title{
Selection of indicators for tonsillectomy in adults with recurrent
} tonsillitis

\author{
Priit Kasenõmm*1,2, Andres Piirsoo ${ }^{3}$, Mart Kull², Mart Kull Jr² and \\ Marika Mikelsaar ${ }^{1}$
}

Address: ${ }^{1}$ Department of Microbiology, Tartu University, Ravila St. 19, Tartu 50411, Estonia, ${ }^{2}$ Department of Otorhinolaryngology, Tartu University Clinicum, Kuperjanovi St. 1, Tartu 51003, Estonia and ${ }^{3}$ Department of General and Molecular Pathology, Medical Faculty, Tartu University, Ravila St. 19, Tartu 50411, Estonia

Email: Priit Kasenõmm* - priit.kasenomm@kliinikum.ee; Andres Piirsoo - andres.piirsoo@ut.ee; Mart Kull - mart.kull@kliinikum.ee; Mart Kull - kullmart@hotmail.com; Marika Mikelsaar - marika.mikelsaar@ut.ee

* Corresponding author

Published: 13 September 2005

BMC Ear, Nose and Throat Disorders 2005, 5:7 doi:10.1 I86/1472-68/5-5-7
Received: 09 April 2005

Accepted: 13 September 2005

This article is available from: http://www.biomedcentral.com/I472-68/5/5/7

(c) 2005 Kasenõmm et al; licensee BioMed Central Ltd.

This is an Open Access article distributed under the terms of the Creative Commons Attribution License (http://creativecommons.org/licenses/by/2.0), which permits unrestricted use, distribution, and reproduction in any medium, provided the original work is properly cited.

\begin{abstract}
Background: We aimed to find some new indicators for tonsillectomy (TE) in adults with recurrent tonsillitis (RT) by exploring whether the frequency of tonsillitis episodes and the length of morbidity period are associated with the macroscopic signs of sclerotic process in tonsils and microbiological data assessed by culture, molecular (PCR) and transmission electron microscopy (EM) methods.
\end{abstract}

Methods: The study involved 62 RT patients admitted for TE (age range 15-35, median 22 years) and 54 healthy volunteers (age range 18-24, median 20 years). The index of tonsillitis (IT) was calculated by multiplying the number of tonsillitis episodes per year by the morbidity period in years. On oropharyngeal examination the presence or absence of three sclerotic signs was evaluated: tonsillar sclerosis, obstruction of tonsillar crypts and scar tissue on the tonsils. The occurrence of Streptococcus pyogenes was assessed by culture and PCR methods in 24 tonsillar core specimens. The samples for EM investigation of crypt epithelium were taken from 10 removed tonsils.

Results: The IT values were in positive correlation with the number of sclerotic signs on oropharyngeal examination $(r=0.325, P=0.010)$. Based on the IT values and the presence or absence of tonsillar sclerosis and obstruction of tonsillar crypts the receiver-operating curve (ROC) was constructed. It revealed that an IT score of 36 is an optimal cut-off value for prediction of sclerotic type tonsils. S. pyogenes was never found by culture, but its presence by PCR in nearly one third (29\%) of diseased tonsillar tissue specimens was tightly associated with longer morbidity. EM revealed coccoid forms of intracellular bacteria in the crypt epithelium, which was accompanied with the damage of tight junctions between epithelial cells.

Conclusion: The index of tonsillitis $\geq 36$, being a combination between the frequency of tonsillitis and the length of morbidity period, predicts the sclerotic process in recurrently inflamed tonsils. Therefore, the high IT values could serve as an indicator for TE in adults. The correlation between the longer morbidity period and the presence of $S$. pyogenes by PCR suggests that persistent infection may have a role in maintenance of recurrent inflammation in tonsils. 


\section{Background}

Recurrent tonsillitis (RT) is a chronic inflammatory process in palatine tonsils. A leading therapeutic approach for such a condition has been tonsillectomy (TE). Traditionally, recommendation for TE has depended primarily on the frequency of tonsillitis episodes. Patients with at least three episodes per year, despite adequate medical therapy, may be considered as candidates for TE, and surgical treatment is definitely recommended for patients with more than four or five episodes per year [1,2]. Adult patients often have fewer or less severe tonsillitis episodes, yet the dominance of other indices of chronic disease, such as poor general health, time loss from school or work, decreased life quality due to systemic effects or comorbid diseases, group A $\beta$-hemolytic streptococcus carriage state, and increased serum concentrations of antibodies, which have also been considered as appropriate indicators for TE [3-5]. Unfortunately, there is no consensus for these arbitrarily used criteria, hinting at a need for more precise indicators.

Palatine tonsils are a part of the mucosa-associated lymphatic tissue (MALT), a specialized compartment of the immune system that serves as a first line of defence against environmental harmful factors, including pathogenic microbes [6]. Paradoxically, palatine tonsils themselves are quite frequently affected by bacterial and viral infections causing local inflammation and systemic reactions. Recurrent or chronic inflammation in the tonsillar tissue results in obstruction of tonsillar crypts due to tissue fibrosis, accompanied by distension of the crypts' bottom and retention of its content $[7,8]$. In our previous study, the sclerotic and inflammatory type tonsils were discriminated, based on the presence or absence of tonsillar sclerosis, obstruction of tonsillar crypts and scar tissue on the tonsils. The sclerotic process in tonsils was further evidenced by increased collagen content. It revealed that sclerotic type tonsils had remarkably lower count of neutrophils in its tissue, which increased the risk for bacteraemia during tonsillectomy [9]. Thus, extensive tissue fibrosis seemed to be a critical point in the RT pathogenesis where the defensive function of tonsils becomes impaired. Unfortunately, there are no studies showing whether the frequency of tonsillitis episodes and the length of morbidity period have an association with sclerotic process in recurrently inflamed tonsils. We suggest that such an approach might be helpful in finding some new indicators for TE.

Despite the high frequency in population, the etiology of RT has remained unclear. The surface and deep bacterial flora of recurrently inflamed tonsils consist of an abundance of potentially pathogenic aerobic and anaerobic bacteria [10-14]. Surprisingly, the isolation rate of Streptococcus pyogenes from adults with RT, the most important pathogen in acute tonsillar infection, is lower by conventional culture methods [15-17]. As the pathogenesis of various infectious diseases has been attributed to intracellularly residing bacteria, applying some modern methods could provide advantages to determine the occurrence of $S$. pyogenes and its role in the pathogenesis of RT.

The aim of this study was to assess whether the frequency of tonsillitis episodes and the length of morbidity period are associated with the macroscopic signs of sclerotic process in tonsils and microbiological data, assessed by culture, molecular (PCR) and transmission electron microscopy (EM) methods in RT patients admitted for TE (RT-TE).

\section{Methods Clinical cohort and follow-up Patients}

The study involved 62 RT-TE patients (age range 15-35, median 22 years; 41 females and 21 males) selected among 486 adults referred for TE due to recurrent attacks of tonsillitis episodes between October to December 2000, March to June and September to December 2001 at the Department of Otorhinolaryngology, Tartu University Clinicum. Every third patient ( $\geq 15$ years of age) was selected from the operation list on two particular days of the week. Each patient had a history of recurrent tonsillitis episodes for at least one year, characterized by sore throat or swollen painful tonsils with fever or symptoms of systemic illness during exacerbations, but the absence of symptoms of possible viral upper respiratory tract infection, such as running nose and cough. As routinely throat cultures were not taken from adults with RT during each exacerbation, the episodes were considered of unknown cause. All patients had been referred for TE by an ENT surgeon from the Department of Otorhinolaryngology. The particular number of tonsillitis episodes per year was not set as an inclusion criterion in the present study. The exclusion criteria were the acute tonsillitis exacerbation, acute respiratory infection, and antibiotic therapy within the two previous months.

\section{Control subjects}

The control group consisted of 54 volunteer students (age range 18-24, median 20 years; 36 female and 18 male) who were not suffering from recurrent tonsillitis episodes. The study had approval from the Tartu University Research Ethics Committee, and in each case written informed consent was obtained from each participant.

\section{Collection of history data and oropharyngeal examination}

In RT-TE patients, the disease history data such as the number of tonsillitis episodes per year, the length of morbidity period in years, presence of documented comorbid diseases, usage of antibiotics and changes in life quality 
due to tonsillitis episodes were collected by one examiner (MK Jr), and the oropharyngeal examinations were performed by another (PK), who was blinded to the type of patients seen. In healthy controls, the same examiner conducted the oropharyngeal examinations separately. On oropharyngeal examination the presence or absence of the three characteristic signs of sclerotic process was evaluated: tonsillar sclerosis, obstruction of tonsillar crypts, and scar tissue on the tonsils. Tonsillar sclerosis was defined as increased tightness of tonsillar and peritonsillar tissue together with the fixation of palatine tonsil in the tonsillar fossa. The obstruction of the tonsillar crypts was documented when narrowing of the crypts' mouth was observed resulting in loss of clear cryptic pattern of the tonsillar surface. The scar tissue on the tonsils was defined as white tissue-spots or streaks on the tonsillar surface.

\section{Analysis of S. pyogenes occurrence in core tonsils Bacteriological analysis}

The occurrence of $S$. pyogenes in tonsillar core tissue was assessed in the first 24 tonsils removed from RT-TE patients. The bacteriological culture was performed according to the previously described method [18]. Briefly, after excision, one of the tonsils was placed in a sterile Petri dish and taken immediately to the microbiology laboratory. For a tonsillar core culture, approximately $0.2 \mathrm{~g}$ of tissue was aseptically excised and homogenized in a sterile mortar with a known amount of pre-reduced phosphate-buffered saline (PBS; pH 7.2) in the anaerobic glove box (Sheldon Manufacturing Inc., USA, with a gas mixture: $5 \% \mathrm{CO}_{2}, 5 \% \mathrm{H}_{2}, 90 \% \mathrm{~N}_{2}$ ) and was further serially diluted $\left(10^{-2}-10^{-7}\right)$. The dilutions were seeded on Columbia horse blood agar plates enriched with streptococcus selective supplement (Oxoid Ldt., UK). All plates were incubated for 48 hours at $36^{\circ} \mathrm{C}$ in an atmosphere enriched with $10 \% \mathrm{CO}_{2}$ in Jouan IG150 incubator (Jouan, France). The culture plates were examined for the growth of $\beta$-hemolytic streptococci and selected colonies were Gram stained and subjected to microscopy. The $\beta$-hemolytic streptococci were distinguished from $\alpha$-hemolytic streptococci by the type of hemolysis and were grouped using streptococcus latex agglutination test (Oxoid Ltd., UK).

\section{PCR amplification}

For molecular detection of $S$. pyogenes, the total genomic DNA was extracted from the tonsillar tissue samples of 24 selected RT-TE patients according to the previously described method [19]. For the amplification of specific $S$. pyogenes mitogenic factor $(m f)$ gene [20], the following primers were used: forward, 5'-CTA CTT GGA TCA AGA CGG-3'; and reverse, 5'-TTA GGG TTT CCA GTC CAT CC$3 '$. The PCR was performed in a $25-\mathrm{ml}$ volume with $\sim 10$ ng DNA sample, in an automated thermal cycler (Biome-

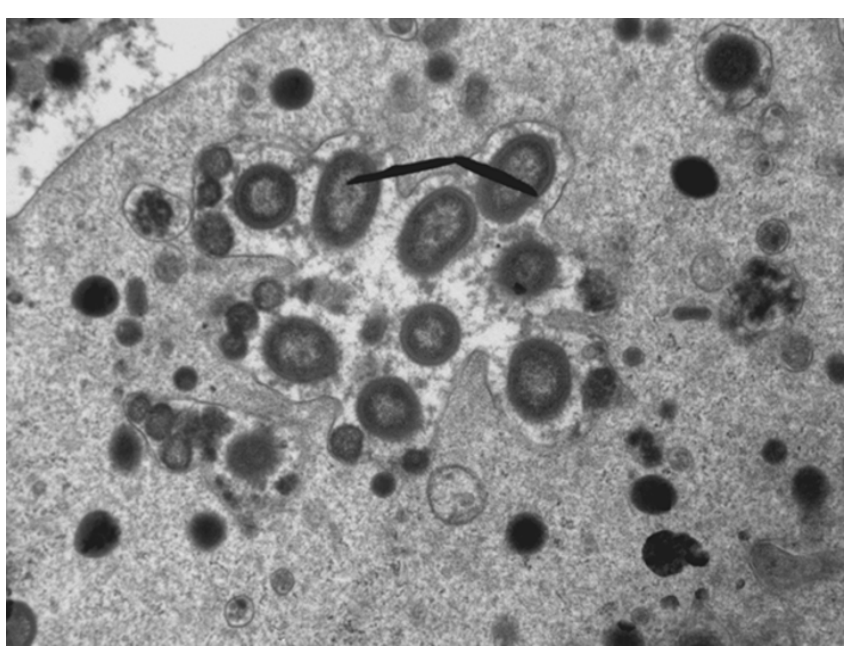

\section{Figure I}

Transmission electron microscopy of the crypt epithelium of palatine tonsils showed coccoid forms of bacteria within epithelial cells (original $\times 10000$ ).

tra, Eppendorf) by using a Ready-To-Go PCR Bead (Amersham Pharmacia Biotech Inc., USA). Extracted DNA of $S$. pyogenes ATCC 19615 served as a positive control.

\section{Transmission electron microscopy}

For detection of the putative intracellular location of bacteria, the transmission electron microscopy (EM) of the crypt epithelium of 10 randomly selected tonsils from RTTE patients was performed. The interactions between epithelial cells, infiltrating nonepithelial cells and bacteria were studied. Approximately $1-\mathrm{mm}^{3}$ samples from PTs were fixed in $2.5 \%$ glutaraldehyde $(0.1 \mathrm{M}$ cacodylate puffer, $\mathrm{pH} 7.4$ ) at $4^{\circ} \mathrm{C}$ for $2.5 \mathrm{~h}$ and postfixed in $1 \%$ osmium tetraoxide. After dehydration through an ethanol series and acetone, samples were embedded in epoxy resin. Sections were cut with ultratome MT-LX (RMC, USA). Semithin sections $(1 \mu \mathrm{m})$ were stained with methylene blue, azure II eosin and basic fuchsin for light microscopy. Ultrathin sections were stained with uranyl acetate and lead citrate and were examined by TEM using Tecnai 10 electron microscope (FEI, Netherlands).

\section{Statistical analyses}

Statistical analyses were performed using 'Excel' (Microsoft Corp.) and 'R' (The R Development Core Team) software, employing Chi-square, Mann-Whitney rank sum and Pearson's rank correlation tests. Comparing the presence of sclerotic signs in RT-TE patients and in healthy controls the sensitivity, specificity, positive (PPV) and negative predictive value (NPV) of the signs were calcu- 


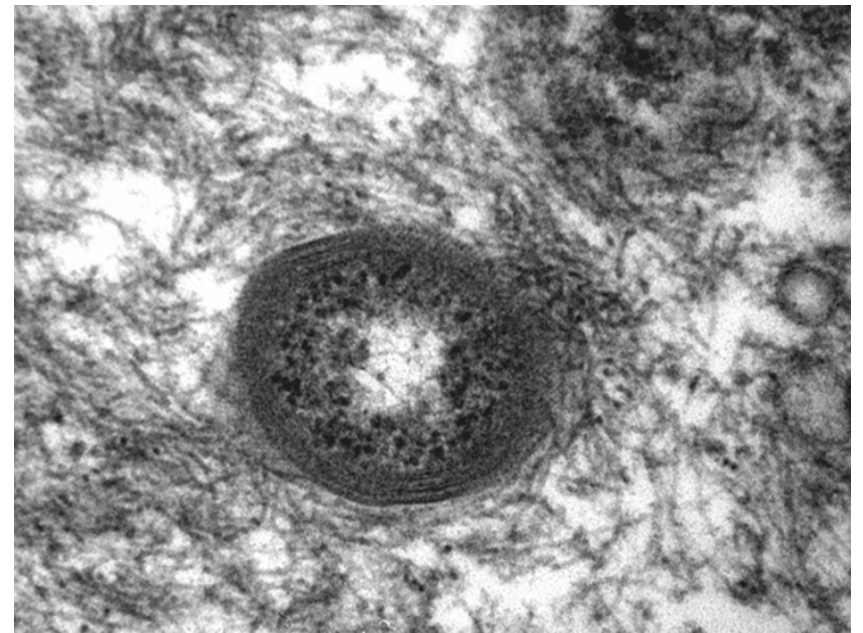

\section{Figure 2}

High power magnification showed that intracellular bacteria were surrounded by cytoplasmatic tonofibrils (original $\times 73000)$.

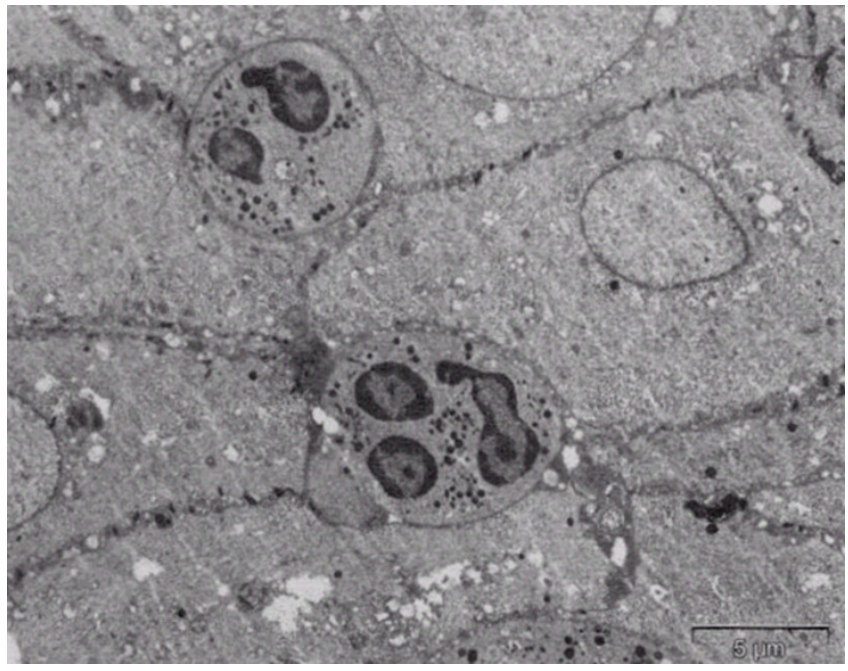

\section{Figure 3}

The intact crypt epithelium contained neutrophilic granulocytes and other nonepithelial cells, which were tightly packed between epithelial cells (original $\times 2100$ ). lated. Based on the disease history data and the presence of sclerotic signs, the receiver-operating curve (ROC) and the area under the curve (AUC) were constructed for prediction of sclerotic type tonsils [21]. All differences were considered statistically significant for P-values less than 0.05 .

\section{Results}

\section{Disease history in RT-TE patients}

Out of 62 RT-TE patients, 26 (42\%) patients had six or more, $10(16 \%)$ had four to five and 26 (42\%) patients had three or less tonsillitis episodes per year. The median number of tonsillitis episodes in the whole group of RTTE patients was 4.5 per year. The duration of morbidity ranged from 1 to 23 years; the median being 6 years. There was no difference in the length of morbidity between patients with four or more and patients with three or less tonsillitis episodes per year; the median being 7 and 5 years respectively. No correlation was found between the frequency of tonsillitis episodes and the duration of morbidity.

The index of tonsillitis (IT) was calculated by multiplying the number of tonsillitis episodes per year by the morbidity period in years [22]. The median IT in the whole group of RT-TE patients was 30 (range 6-138). The comorbid disease was documented in 14 (22\%) RT patients: rheumatic heart disease in 7, unspecified polyarthritis in 5, rheumatoid arthritis and glomerulonephritis both in one patient.

\section{Associations between residing bacteria and epithelial damage}

Occurrence of S. pyogenes in tonsillar core tissue

S. pyogenes was not cultivated from any of the core tonsils, but it was found in 29\% (7 out of 24) of the diseased tonsillar tissue specimens by PCR.

\section{$E M$}

EM revealed various morphotypes of bacteria on the surfaces of epithelial cells, and many of them were in intimate contact with the cell membrane. Many coccoid forms of bacteria were either penetrating into the cells or were locating completely intracellularly (Figure 1). The bacteria within cells were usually intact and surrounded by cytoplasmatic tonofibrils (Figure 2 ).

The nonepithelial cells in the intact crypt epithelium, including neutrophilic granulocytes, were tightly packed between epithelial cells (Figure 3). However, in case of damage of tight junctions between epithelial cells, with remaining desmosomes only on the projections, free spaces between adjacent epithelial cells appeared (Figure 4 ). These gaps were frequently occupied by degenerating granulocytes with intact granules and bacteria (Figure 5).

\section{Optimal cut-off score of IT}

As expected, the presence of sclerotic signs on oropharyngeal examination was more common in RT-TE patients than in the healthy controls. The most common sign in RT-TE patients was the scar tissue on tonsils, but it was 
Table I: Prevalence of sclerotic signs in RT-TE patients and healthy controls with their sensitivity, specificity and predictive values.

\begin{tabular}{|c|c|c|c|c|c|c|}
\hline \multirow[b]{2}{*}{$\begin{array}{l}\text { Signs of sclerotic } \\
\text { process }\end{array}$} & \multicolumn{2}{|c|}{ Prevalence, $\mathrm{n}(\%)$} & \multirow[b]{2}{*}{ Sensitivity } & \multirow[b]{2}{*}{ Specificity } & \multirow[b]{2}{*}{ PPVa } & \multirow[b]{2}{*}{$N P V^{b}$} \\
\hline & $\begin{array}{l}\text { Patients } \\
(\mathrm{n}=62)\end{array}$ & $\begin{array}{l}\text { Healthy controls } \\
\qquad(\mathrm{n}=54)\end{array}$ & & & & \\
\hline Tonsillar sclerosis & $29(47)$ & $2(4)$ & 0.47 & 0.96 & 0.94 & 0.61 \\
\hline $\begin{array}{l}\text { Crypts' } \\
\text { obstruction }\end{array}$ & $34(55)$ & $8(15)$ & 0.55 & 0.85 & 0.81 & 0.62 \\
\hline $\begin{array}{l}\text { Scar tissue on } \\
\text { tonsils }\end{array}$ & 49 (79) & II (20) & 0.79 & 0.80 & 0.82 & 0.77 \\
\hline
\end{tabular}

RT-TE patient - patients who were referred for tonsillectomy due to recurrent tonsillitis episodes, PPV - positive predictive value, NPV - negative predictive value

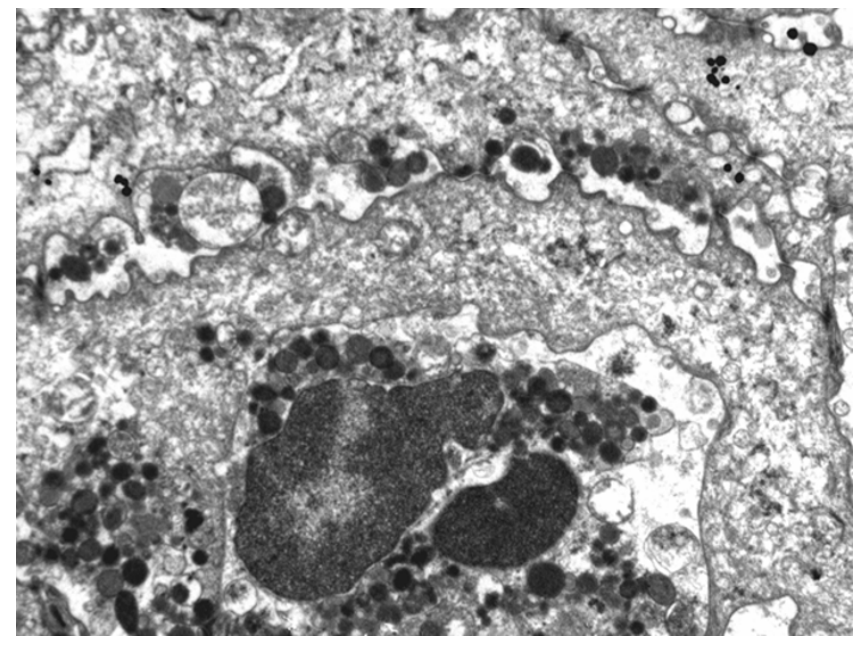

Figure 4

Damage of tight junctions between epithelial cells, with remaining desmosomes only on the projections, led to formation of free spaces between adjacent epithelial cells (original $\times 7000)$.

also frequently found in healthy controls. The tonsillar sclerosis and obstruction of crypts were less frequently found in healthy controls, but were observed in nearly half of RT-TE patients. Accordingly, tonsillar sclerosis had the highest specificity and PPV, while scars on tonsils showed the highest sensitivity and NPV (Table 1). We found that the higher frequency of tonsillitis episodes was in strong correlation with the occurrence of obstructed tonsillar crypts and the longer morbidity period with tonsillar sclerosis and with the presence of S. pyogenes in tonsillar tissue by PCR (Table 2). Further, the higher IT values were expectedly in good correlation with the number of sclerotic signs on oropharyngeal examination $(r=0.325$, $P=0.010)$. The frequency of tonsillitis episodes per year

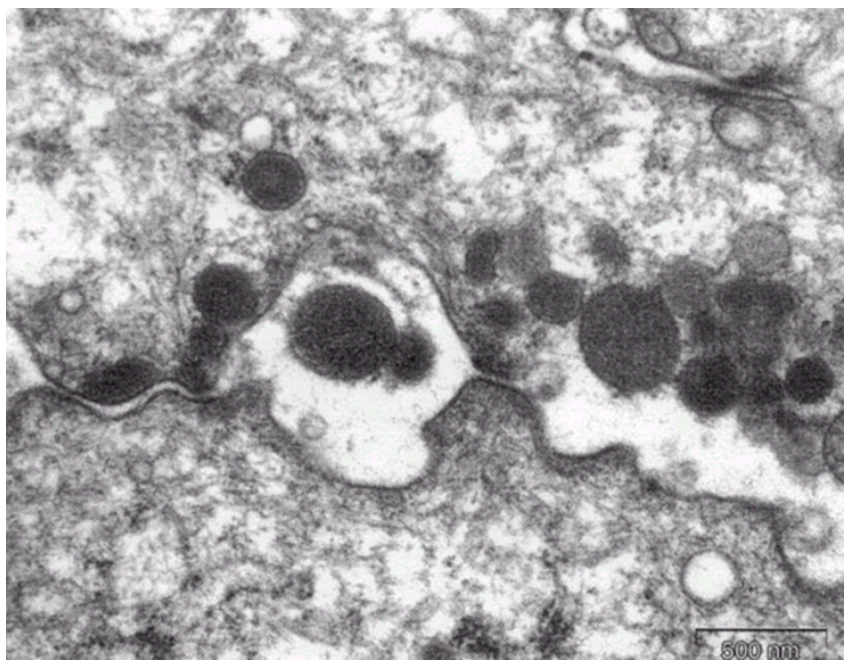

\section{Figure 5}

High power magnification showed that the gaps between epithelial cells were occupied by degenerating granulocytes and their intact granules (original $\times 27000$ ).

and the length of morbidity period showed no correlation with scars on the tonsillar surface. The presence of comorbid diseases had no association with the sclerotic signs and PCR data.

Based on the IT values and the presence or absence of tonsillar sclerosis and obstruction of tonsillar crypts the ROC curve with AUC was constructed to ascertain the cut-off score of IT. It revealed that an IT score of 36 is an optimal cut-off value for prediction of sclerotic type tonsils (AUC $=0.716)$. It had a sensitivity of $52.5 \%$, specificity of $86.1 \%$, positive predictive value of $87.5 \%$ and negative predictive value of $50.0 \%$ (Figure 6 ). 
Table 2: Correlation between the patients' disease history data, the presence of sclerotic signs in tonsils and PCR data on Streptococcus pyogenes.

\begin{tabular}{|c|c|c|c|c|}
\hline \multirow[b]{2}{*}{ History data } & \multicolumn{3}{|c|}{ Signs of sclerotic process } & \multirow[b]{2}{*}{ PCR for S. pyogenes } \\
\hline & Tonsillar sclerosis & Obstruction of crypts & All three signs & \\
\hline Frequency of tonsillitis episodes & NS & $\begin{array}{l}R_{P}=0.354 \\
P=0.005\end{array}$ & $\begin{array}{l}R_{p}=0.299 \\
P=0.018\end{array}$ & NS \\
\hline Morbidity period & $\begin{array}{l}R_{p}=0.437 \\
P=0.001\end{array}$ & NS & $\begin{array}{l}R_{p}=0.318 \\
P=0.011\end{array}$ & $\begin{array}{l}R_{p}=0.503 \\
P=0.012\end{array}$ \\
\hline Index of tonsillitis & $\begin{array}{l}R_{p}=0.384 \\
P=0.002\end{array}$ & NS & $\begin{array}{l}R_{p}=0.325 \\
P=0.01\end{array}$ & NS \\
\hline
\end{tabular}

$R_{p}$ - Pearson correlation coefficient. NS - statistically nonsignificant correlation

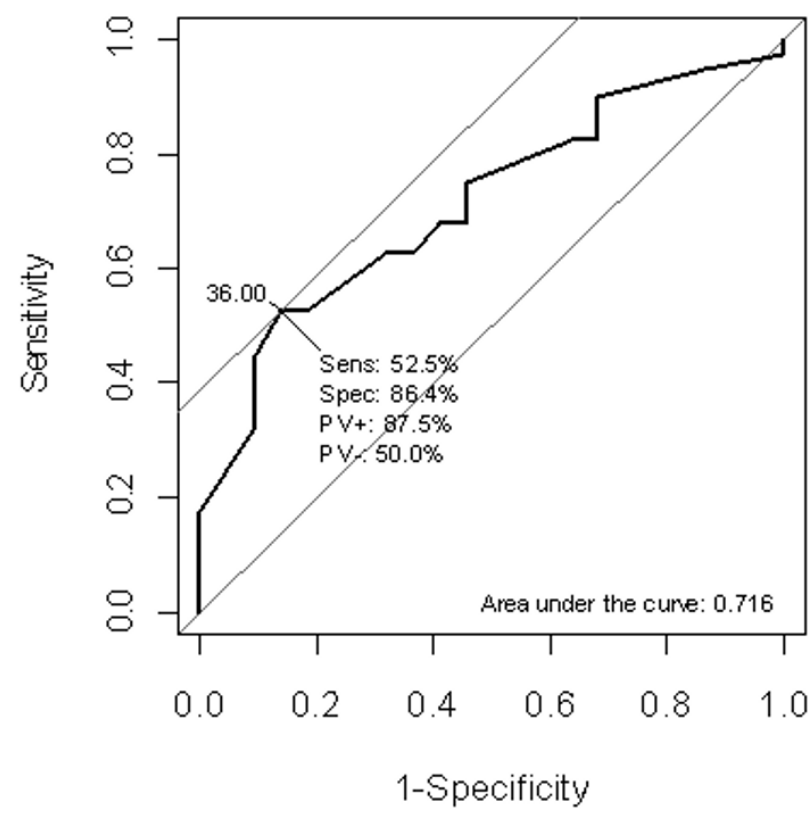

Figure 6

The ROC curve of IT scores for prediction of sclerotic type tonsils. An optimal cut-off score of IT was 36 (AUC = 0.716), with sensitivity of $52.5 \%$, specificity of $86.1 \%$, positive predictive value of $87.5 \%$ and negative predictive value of $50.0 \%$.

Finally, out of 26 (42\%) RT-TE patients with only three or less tonsillitis episodes per year, 13 had tonsillar sclerosis and obstruction of tonsillar crypts on oropharyngeal examination; one patient had a documented rheumatic fever and another one positive PCR for S. pyogenes. The remaining 11 patients with lower rate of recurrences had only the scars on their tonsils or had no signs of sclerotic process. None of them had documented comorbid dis- eases or evidences of $S$. pyogenes persistence in their tonsils.

\section{Discussion}

The present study revealed that the higher frequency of tonsillitis episodes per year has a strong correlation with the presence of obstructed tonsillar crypts while the longer disease history correlates well with the presence of tonsillar sclerosis on oropharyngeal examination. Generally, these findings are in accordance with current knowledge of RT pathogenesis. The continuous exacerbations of chronic inflammation in tonsillar tissue come in long term down to parenchymal fibrosis, followed by stenosis of branched, blind-ended and narrow tonsillar crypts $[7,8]$. The subsequent retention of crypts' contents sets up an ideal culture medium for microorganisms, resulting in the formation of small abscesses, sacks full of different microorganisms. The obstruction of tonsillar crypts and their chronic suppuration potentially promote more easily the exacerbations of chronic inflammation than widely opened and freely drained crypts. However, the present study demonstrated that sclerotic type tonsils can be expected not only in patients with high number of tonsillitis episodes per year, but also in patients with lower number of episodes if combined with long morbidity period. The signs of sclerotic process in tonsils were found in a half of RT-TE patients with only three or less tonsillitis episodes per year. It indicates that a gradual accumulation of exacerbations after long years of suffering is also a factor for the development of sclerotic type tonsils.

As the parenchymal fibrosis leads to lowered count of neutrophils in tonsillar tissue, increasing the risk for spread of bacteria into the bloodstream and infection generalization [9], removal of such functionally compromised tonsils could be justified. However, considering the sclerotic signs as the only indicator for TE, particularly in adults with lower rate of tonsillitis episodes, may lead to an overestimation of the need for surgery. Although the 
sclerotic signs were very frequently found in RT-TE patients, they were also encountered in a significant proportion of healthy persons. For instance, as the scars were commonly found on tonsils in both groups, it had low specificity and PPV for RT diagnosis. Therefore, the recommendations for TE should be based on detailed disease history, taking both the frequency of tonsillitis episodes per year and the length of morbidity period into account, and the presence of sclerotic signs could only strengthen the decision.

In order to add up different disease history data, the frequency of tonsillitis episodes per year was multiplied by the morbidity period in years. Basically, it represents a total number of tonsillitis episodes the patient has ever had and was called the index of tonsillitis in an earlier study [22]. Although it seemed to be successful to characterize RT severity in adults, a specific cut-off score of IT as an indicator for tonsillectomy was not provided. In the present study, the IT values were compared with the presence or absence of most characteristic sclerotic signs, the tonsillar sclerosis and obstruction of tonsillar crypts, in order to construct the ROC curve for prediction of sclerotic type tonsils. An optimal cut-off score of IT was found to be 36, which had balanced sensitivity, specificity and predictive values. This cut-off score indicates that a minimum of 36 tonsillitis episodes could be enough for the development of sclerotic type tonsils. We suggest that specificity of $86.1 \%$ and PPV of $87.5 \%$ of this score are high enough to use it for differentiating patients with advanced tonsillitis from less severe cases.

The interesting finding in the present study was that nearly one-third of culture negative tonsillar core specimens were positive for $S$. pyogenes by PCR. The failure of conventional culture to reveal the presence of $S$. pyogenes has been attributed to its ability for intracellular penetration [24-26]. EM revealed several coccoid forms of intracellular bacteria in the crypt epithelium of diseased tonsils, which was frequently accompanied with the damage of connections between epithelial cells, called tight junctions. Although the type of intracellular bacteria is unknown, a correlation between the presence of S. pyogenes by PCR and the longer morbidity period of RT suggests that hidden persistence of $S$. pyogenes in tonsils may in some cases be responsible for continuous inflammation in its tissue and formation of sclerosis.

In the pathogenesis of concomitant inflammatory diseases of other tissues and organs, such as glomerulonephritis and IgA nephropathy, reactive and rheumatoid arthritis, chronic inflammatory and autoimmune neurological disorders, the key role has been attributed to $S$. pyogenes [27-31]. The high rate of comorbid diseases in our RT-TE patients suggest that TE is often undertaken to elim- inate the reservoir of putative pathogen, e.g. S. pyogenes, despite a negative throat culture. Seemingly, one of the solutions to prevent repeated attacks of tonsillar infections in the early stages of RT is to apply treatment plans with antibiotics effective against intracellular bacteria, particularly among patients with a high-risk for comorbidity. Among our patients, the candidates for such a conservative therapy could have been $18 \%$ of patients who had three or less tonsillitis episodes, but had neither the signs of sclerotic process on oropharyngeal examination nor supporting comorbidity yet evidence of $S$. pyogenes in tonsillar tissue.

We conclude an IT score $\geq 36$, being a combination between the frequency of tonsillitis and the length of morbidity period, predicts the sclerotic process in recurrently inflamed tonsils. Therefore, the high IT values could serve as an indicator for TE in adults. The correlation between the longer morbidity period and the presence of $S$. pyogenes by PCR suggests that persistent infection may have a role in maintenance of recurrent inflammation in tonsils.

\section{Competing interests}

The author(s) declare that they have no competing interests.

\section{Authors' contributions}

PK was principal investigator, carried out oropharyngeal examinations, collected samples for microbiological and molecular studies, performed PCR reactions, participated in electronmicroscopical studies, and drafted the manuscript. AP carried out the electronmicroscopical studies and interpreted the data. MK participated in the design of the study and revised critically the manuscript. MK Jr. carried out collection of disease history data from patients and participated in microbiological and molecular studies. MM coordinated the study and helped to draft the manuscript. All authors read and approved the final manuscript.

\section{Acknowledgements}

The authors wish to thank the members of the Department of Otorhinolaryngology, Tartu University Clinicum for their contribution and providing study patients, and Krista Fischer from the Department of Public Health, Tartu University for excellent help performing the statistical analyses. This work was supported by Grant No. 4898 from the Estonian Science Foundation, Estonian Target funding No. 0418 from the Estonian Ministry of Education and the Centre of Molecular and Clinical Medicine, Faculty of Medicine, University of Tartu.

\section{References}

I. American Academy of Otolaryngology-Head and Neck Surgery [http://www.entnet.org]

2. Scottish Intercollegiate Guidelines Network: Management of sore throat and indications for tonsillectomy. A national clinical guideline. Edinburgh 1999. 
3. Mui S, Rasgon BM, Hilsinger RL: Efficiacy of tonsillectomy for recurrent throat infection in adults. Laryngoscope 1998, 108:1325-1328.

4. Bhattacharyya N, Kepnes LJ, Shapiro J: Efficacy and quality-of-life impact of adult tonsillectomy. Arch Otolaryngol Head Neck Surg 200I, I 27: I347-I 350

5. Bhattacharyya N, Kepnes LJ: Economic benefit of tonsillectomy in adults with chronic tonsillitis. Ann Otol Rhinol Laryngol 2002, I I I:983-988.

6. Perry ME, Whyte A: Immunology of the tonsils. Immunol Today 1998, 19:4|4-42|.

7. Michaels L: Ear, nose and throat histopathology New York: SpringerVerlag; 200I.

8. Altemani A, Endo LH, Chone C, Idagawa E: Histopathological concept of chronic tonsillitis in children. Acta Otolaryngol (Stockh) 1996:14-16.

9. Kasenõmm P, Mesila I, Piirsoo A, Kull M, Mikelsaar M, Mikelsaar R-H: Macroscopic oropharyngeal signs indicating impaired defensive function of palatine tonsils in adults suffering from recurrent tonsillitis. APMIS 2004, I | 2:248-256.

10. Surow JB, Handler SD, Telian SA, Fleisher GR, Baranak CC: Bacteriology of tonsil surface and core in children. Laryngoscope 1989 , 99:26I-266.

II. Gaffney RJ, Freeman DJ, Walsh MA, Cafferkey MT: Differences in tonsillar core bacteriology in adults and children: a postoperative study of $\mathbf{2 6 2}$ patients. Respir Med I99I, 85:383-388.

12. Mitchelmore IJ, Reilly PG, Hay AJ, Tabaqchali S: Tonsil surface and core cultures in recurrent tonsillitis: prevalence of anaerobes and beta-lactamase producing organisms. Eur J Clin Microbiol Infect Dis 1994, 13:542-548.

13. Brook I, Yokum P, Foote PA: Changes in the core tonsillar bacteriology of recurrent tonsillitis: 1977-93. Clin Infect Dis 1995, 21:171-176

14. Stjernquist-Desatnik A, Holst E: Tonsillar microbial flora: comparison of recurrent tonsillitis and normal tonsils. Acta Otolaryngol (Stockh) 1999, I 1 9:102-106.

15. Brook I, Yocum P: Bacteriology of chronic tonsillitis in young adults. Arch Otolaryngol 1984, I 10:803-805.

16. Lildholdt T, Doessing $H$, Lyster M, Outzen KE: The natural history of recurrent acute tonsillitis and a clinical trial of azitromycin for antibiotic prophylaxis. Clin Otolaryngol 2003, 28:37I-373.

17. Podbielski A, Beckert S, Schattke R, Leithauser F, Lestin F, Gossler B, Kreikemeyer B: Epidemiology and virulence gene expression of intracellular group A streptococci in tonsils of recurrently infected adults. Int J Med Microbiol 2003, 293:179-190.

18. Kasenõmm P, Kull M, Mikelsaar M: Association between tonsillar core microflora and post-tonsillectomy bacteremia. Microb Ecol Health Dis 2002, 14:122-127.

19. Louie L, Simor AE, Louie M, McGeer A, Low DE: Diagnosis of group $A$ streptococcal necrotizing fasciitis by using PCR to amplify the streptococcal pyrogenic exotoxin B gene. J Clin Microbiol 1998, 36: I769-I77|.

20. Iwasaki M, Igarashi H, Hinuma $Y$, Yutsudo T: Cloning, characterization and overexpression of a Streptococcus pyogenes gene encoding a new type of mitogenic factor. FEBS Lett 1993, 331:187-192.

21. Van der Schouw YT, Verbeek AL, Ruijs JH: ROC curves for the initial assessment of new diagnostic tests. Fam Pract 1992, 9:506-5II.

22. Fujihara K, Goto H, Hotomi M, Kobayashi M, Hayashi M, Tamura S, Kuki K, Yamanaka N: Immunological derangement in tonsils with recurrent infections. A study of co-stimulatory factors on tonsillar B lymphocytes. International Concress Series 2003, I 257:49-53.

23. Becker W, Naumann HH, Pfaltz CR: Ear, nose, and throat diseases New York: Thieme Medical Publishers Inc; 1994.

24. La Penta D, Rubens G, Chi E, Cleary PP: Group A streptococci efficiently invade human respiratory epithelial cells. Proc Natl Acad Sci USA 1994, $91: 12115-12119$.

25. Osterlund A, Popa R, Nikkila T, Scheynius A, Engstrand L: Intracellular reservoir of Streptococcus pyogenes in vivo: a possible explanation for recurrent pharyngotonsillitis. Laryngoscope 1997, 107:640-647.

26. Norrby-Teglund $A$, Kotb M: Host-microbe interactions in the pathogenesis of invasive group A streptococcal infections. I Med Microbiol 2000, 49:849-852.
27. Bisno AL: Group A streptococcal infections: the changing scene. Curr Opin Infect Dis 1995, 8: I 17-I22.

28. Kobayashi S, Tamura N, Akimoto T, Ichikawa G, Xi G, Takasaki Y, Hashimoto $\mathrm{H}$ : Reactive arthritis induced by tonsillitis. Acta Otolaryngol Suppl 1996, 523:206-2II.

29. Swedo SE, Leonard HL, Garvey M, Mittleman B, Allen AJ, Perlmutter $\mathrm{S}$ : Pediatric autoimmune neuropsychiatric disorders associated with streptococcal infections: clinical description of the first 50 cases. Am J Psychiatry 1998, 155:264-27I.

30. Harsha WJ, Goco PE, Crawford JV: Remission of chronic inflammatory demyelinating polyneuropathy following tonsillectomy. Ear Nose Throat J 2003, 82:520-521.

31. Kawano M, Okada K, Muramoto H, Morishita H, Omura T, Inoue R, Katajima S, Katano K, Koni I, Mabuchi H, Yachie A: Simultaneous, clonally identical $\mathbf{T}$ cell expansion in tonsil and synovium in a patient with rheumatoid arthritis and chronic tonsillitis. Arthritis Rheum 2003, 48:2483-2488.

\section{Pre-publication history}

The pre-publication history for this paper can be accessed here:

http://www.biomedcentral.com/1472-6815/5/7/prepub

Publish with BioMed Central and every scientist can read your work free of charge

"BioMed Central will be the most significant development for disseminating the results of biomedical research in our lifetime. "

Sir Paul Nurse, Cancer Research UK

Your research papers will be:

- available free of charge to the entire biomedical community

- peer reviewed and published immediately upon acceptance

- cited in PubMed and archived on PubMed Central

- yours - you keep the copyright

Submit your manuscript here:

http://www.biomedcentral.com/info/publishing_adv.asp
BioMedcentral 